\title{
Topic 13
}

\section{Interdependencies of Critical Infrastructures}

\author{
Organiser:
}

Rune Gustavsson

Blekinge Institute of Technology, BTH, Sweden

Rune.Gustavsson@bth.se

Our society depends increasingly on reliable and sustainable infrastructure. Due to globalisation and deregulations those infrastructures are becoming more and more interdependent and intervened. A good example of this interdependency is the emerging embedding of ICT (Information and Communication Infrastructures) into power nets.

Existing power nets have proved to be unexpectedly vulnerable as we have recently witnessed by large and costly power blackouts in Europe and the US. Vulnerabilities of Internet are also a well known costly and alarming fact of, e.g., e-business. As a matter of fact, we also know that power blackouts also cause break-downs of information networks. We also have indications that malicious Internet code (virus or Trojans) might have caused, or contributed to, power blackouts.

The following papers were selected for presentation; however, final papers were not available at press time:

Power networks as a critical infrastructure

Nouredine Hadjsaid

Distribution generation as a stabilization factor of power grids

Christophe Andrieu

The role of supporting information infrastructures of a virtual utility

Rune Gustavsson

Challenges of future virtual power grids

Nouredine Hadjsaid 